\title{
Professores em formação, formadores de professores: que profissão ensinam os cursos de graduação em História?
}

Teachers in training, professors of teachers: what profession is taught in History university courses?

Aryana Lima Costa*

\section{RESUmo}

O presente artigo busca refletir sobre os fundamentos que pautam a formação de profissionais de História no ensino superior. Para tanto, nos baseamos nas conclusões obtidas em dois momentos: no primeiro trabalhamos com os resultados de trabalhos de alunos de graduação sobre como planejariam suas aulas; no segundo, nos utilizamos de depoimentos de professores universitários sobre como planejam suas aulas para um curso de História. Assim, dispomos de falas tanto de professores em formação quanto de formadores de professores de História. Esses casos nos permitiram verificar a permanência de práticas docentes presenciadas durante a vida escolar desses sujeitos, e assim refletimos sobre a organização dos cursos de graduação em História e a metodologia de ensino nesse nível.

Palavras-chave: metodologia do ensino de História; formação de professores; ensino superior.

\section{Abstract}

The present article reflects upon the foundations that guide the formation of History professionals in universities. To do so, we base ourselves on the conclusions taken from two moments: the first one in which we work with the results of students' essays on how to plan their History classes, and the second one in which we use statements of university professors on how they plan their classes, so that we have both experiences from teachers being trained and from the professors who train future teachers. From these cases, we conclude for the permanence of practices teaching history marked by the school experiences of these subjects, from which we reflect upon the organization of the History university courses and the teaching of History on this level of education.

Keywords: methodology of teaching History; teacher's training; higher education.

\footnotetext{
* Universidade do Estado do Rio Grande do Norte, Departamento de História/Fafic (DHI/Uern). Campus Universitário Central. BR 110, km 48, Rua Prof. Antônio Campos, Costa e Silva. 59610090 Mossoró - RN - Brasil. aryanacosta@gmail.com
} 
Em que medida o conhecimento histórico pauta efetivamente a formação dos futuros profissionais de História?

Compreender o espaço específico de formação de historiadores - ou seja, as graduações em História - importa se pretendemos cada vez mais investigar o papel que cabe aos historiadores ou que é exercido por eles, e também o que produzem, tendo em vista que esses profissionais estão cada vez mais conscientes de que as relações que as sociedades estabelecem com o tempo não necessariamente passam pelos resultados específicos da academia. Esse movimento é reforçado ainda pelo contexto das inúmeras discussões em torno da definição do perfil do historiador, da luta pela regulamentação da profissão e da crescente discussão em torno do que seriam uma história e um historiador públicos.

Norteia-nos o chamamento que Joana Neves faz em outro texto, "Participação da comunidade, ensino de História e Cultura Histórica", ao defender que "mais do que nunca os historiadores têm a responsabilidade de definir o seu próprio, específico e intransponível papel, bem como equacionar a relação entre conhecimento acadêmico ou cientificamente produzido e as outras formas de produção de saber, na construção da cultura histórica". ${ }^{1}$

Como estamos formando nossos historiadores? O interesse aqui está em, por meio do ensino superior de História, entender como nos utilizamos do conhecimento histórico e, assim, mantemos nossa especificidade e forjamos um perfil - nossa identidade - nos cursos de graduação.

Retomando Joana Neves, "A história produz um conhecimento educativo por definição” (Neves, 2000-2001, p.36), logo, não pode estar alheia à sociedade, com quem sempre precisa dialogar. "Mesmo as pesquisas de ponta, por mais que indiquem interesses ainda restritos a um único especialista, uma vez produzindo resultados, acrescentarão, de um modo ou de outro, algum aporte à cultura histórica” (p.38). O ensino de História em nível superior trabalha para contestar a tendência à constituição de uma cultura histórica "sem o concurso ou até em oposição aos profissionais da área”, levando-nos à autorreflexão, à definição de nossa posição, ao lugar do conhecimento histórico, à "participação dos historiadores de ofício na discussão de intrincadas questões colocadas pelo ensino de história” (p.41).

Definido então o nosso quinhão, por meio de que mecanismos nosso espaço é conservado, alimentado e gerado pelo ensino superior de História? 
Quais os mecanismos por trás dos funcionamentos dos cursos de graduação que interferem na formação de novos profissionais, na produção de novo conhecimento histórico, na delimitação até do próprio campo?

Buscaremos responder a essas perguntas com base em dois estudos de caso relatados a seguir.

\section{OS PROFESSORES EM FORMAÇÃO}

As conclusões deste tópico foram possíveis mediante a opção de se transformar em espaço de observação e reflexão sobre a formação de profissionais de História a disciplina de Metodologia do Ensino de História, ministrada no $3^{\circ}$ período do curso de História da Universidade do Estado do Rio Grande do Norte, no núcleo avançado de João Câmara. Isso se deu com base no planejamento de atividades para a disciplina, apresentado no primeiro dia de aula à turma, que aceitou participar.

Os objetivos estabelecidos para a disciplina foram: estabelecer relações entre o conhecimento histórico aprendido nas demais disciplinas do curso e os objetivos do ensino de história para o ensino fundamental e médio; desenvolver autonomia na seleção e elaboração de conteúdos históricos para atuação em espaços escolares; e produzir material didático para o ensino de história.

A intenção inicial era reproduzir ao longo das 60 horas disponíveis o ciclo percorrido pelo professor de História: discussão dos conteúdos curriculares e objetivos do ensino de História; estudo da história do ensino de História no Brasil e a proposta de história nos documentos curriculares atuais; reconhecimento das relações entre conhecimento histórico acadêmico e a história ensinada; usos do livro didático e historiografia didática; métodos e ensino de história; uso de recursos como fontes históricas, e, por fim, avaliação.

Dado o tamanho da turma, os alunos se dividiram em duplas no início do semestre. As aulas foram organizadas de modo que tivéssemos um momento de discussão teórica, seguido de outro de produção prática. Essa produção deveria se basear no tema da discussão teórica e versar sobre o tema escolhido pela dupla. Ao final do semestre, todos os textos produzidos pelas duplas seriam reunidos, de modo a formar uma proposta de material didático referente aos temas escolhidos. Estes começariam pela justificativa da escolha da temática de acordo com os objetivos do ensino de História; passariam 
pela apresentação daquela temática na historiografia acadêmica e didática; agregariam uma proposta de atividade em sala de aula, utilizando-se de algum recurso didático tratado enquanto fonte histórica; e finalizariam com propostas de avaliações, também referentes ao tema.

Para as discussões das aulas teóricas tivemos como auxílio leituras de textos de autores da área. Nesses momentos realizávamos discussões de cunho mais generalista, abrangendo a História e o ensino de História em geral. Entretanto, os alunos eram orientados a já buscarem realizar as leituras e participar dos debates estabelecendo relações entre as discussões travadas e suas próprias temáticas. A aula seguinte era reservada à discussão entre as duplas, sob a orientação da docente, ao final da qual deveria ser entregue uma produção escrita que serviria como material para avaliação.

Tendo em vista a proximidade entre professora e alunos promovida pela constante orientação e o contato contínuo com as produções discentes, a avaliação pôde ser realizada de modo processual, que se caracterizou pelas notas atribuídas aos trabalhos, mas também pelos momentos para discussão e reorientação dos textos entregues e, por vezes, envolvendo até sua reelaboração, após cada momento de produção prática.

É preciso registrar o empenho com que a turma se dedicou às atividades. A alternância entre aulas teóricas e produção prática revelou-se desafiadora quando da aproximação do final do semestre, mas a turma manteve até o final das atividades o mesmo nível de dedicação demonstrado no início, e a isso devemos atribuir em grande parte o êxito dessa experiência e a consequente oportunidade de compartilhá-la aqui.

É preciso considerar os ruídos do processo ensino-aprendizagem, não só no âmbito da comunicação entre docente e alunos, por isso tomaremos algumas situações como pontos de reflexão:

Já na primeira aula depois da apresentação da proposta, solicitou-se aos alunos que escolhessem uma temática na História. Não foram estabelecidas regras - poderiam escolher qualquer assunto, aquele de que mais gostassem ou aquele ao qual tivessem mais acesso. Dos 17 trabalhos, 16 se ativeram ao processo histórico, versando sobre recortes cronológicos da História, e um poderia ser enquadrado na categoria da meta-história, visto que elegeu as fontes históricas como tema de trabalho. Digno de nota também é o fato de alguns grupos terem retirado seus temas de índices de livros didáticos. Assim, 
reunimos uma lista bastante canônica de assuntos: América pré-colombiana; A corte portuguesa no Brasil; Ditadura Militar (1964-1974); Revolução Francesa; A Independência do Brasil; Revolução Industrial; Escravidão no Brasil Colonial; Chegada dos portugueses ao Brasil. Outros trabalhos caminharam em sua temática para uma verticalidade: Censura na Ditadura Militar; Revolução Industrial e consumismo; Relações de poder na sociedade feudal; Educação na Ditadura Militar; Religião egípcia; Desigualdade social no antigo Egito e no século XXI; por fim, Fontes históricas: revistas e livros.

A primeira atividade prática foi a justificativa da escolha do assunto: a) Por que estudar esse assunto é importante para o meu aluno?; b) Como essa temática se relaciona com os objetivos do ensino fundamental e médio?; e c) Quais habilidades do pensamento histórico se pretende trabalhar?”. Estas perguntas deveriam ser respondidas com base nas discussões realizadas em sala de aula a respeito da história do ensino de História e da proposta de História nos currículos atuais.

Reproduzimos a seguir algumas das respostas a cada uma dessas perguntas, refletindo a tônica geral dos trabalhos:

a) Partindo do pressuposto de que a História deve contribuir para a formação do cidadão crítico, trabalharemos a temática de forma discursiva e dinâmica, proporcionando ao aluno o desenvolvimento do senso crítico ... Através do tema abordado, pretendemos que o aluno aprenda de forma interativa, compreendendo o período de transição da época $[\mathrm{em}]$ que aconteceu o ocorrido até os dias atuais...

b) Os objetivos deparados com relação ao ensino médio buscam o estímulo do aluno para que o mesmo possa obter mais conhecimentos acerca do que está sendo estudado, o docente tem a preocupação de formar cidadãos críticos, com seus próprios conceitos sobre a vida e o mundo ... Nosso objetivo estará voltado para o ensino fundamental, trabalhando o tema de forma dinâmica, trazendo as discussões acerca de como e o que provocaram as mudanças e permanências que aconteceram nesse período, tentando junto com os alunos um senso de criticidade...

c) A partir da referente temática pretendemos desenvolver a habilidade do aluno conseguir ter criticidade na temporalidade, visando o passado e 
o presente, tornando o mesmo apto a questionar lucidamente as mudanças e imposições ocorrentes no período. Devemos incentivar nossos alunos à pesquisa, fazendo com que este alcance um desprendimento básico do livro didático, objetivando habilidade críticas diante das fontes e fazendo com que este busque confrontá-las entre si para obter uma análise concreta e eficaz.

Lembrando mais uma vez a complexidade do processo ensino-aprendizagem, sendo necessário computar o papel da docente na compreensão pelos alunos do que esteja sendo exigido, e também a própria relação que os alunos estabelecem com o conhecimento universitário, detectamos alguns pontos de partida comuns.

O primeiro é uma constante referência ao desenvolvimento de um senso crítico pelos alunos como um dos objetivos do ensino de História, seja na pergunta referente aos objetivos do ensino fundamental, seja na pergunta relativa às habilidades do pensamento histórico. O que não se verificou com igual incidência foi a explicitação de como aquela temática em especial deveria contribuir para o desenvolvimento dessa criticidade.

Percebe-se também uma preocupação com o que poderíamos chamar de conteúdo factual: compreender o período, o que causou o acontecimento, o que provocou as mudanças e permanências. Mas outras habilidades do pensamento histórico aparecem, ainda que com menos frequência: reconhecimento de mudanças e permanências e uso de fontes para construção do conhecimento, evidenciando um deslocamento da preocupação com aqueles conteúdos factuais para os mecanismos de construção do conhecimento histórico. É possível que esse despertar para habilidades outras que não referentes ao conhecimento do conteúdo factual tenha origem nas discussões em sala de aula e na orientação individual. Entretanto, já nas orientações, verificamos dificuldade por parte dos alunos em compreender o que seriam habilidades do pensamento histórico. E, apesar de uma suposta proposta renovadora de objetivos que esses textos iniciais nos apontam, é interessante confrontá-los com as sugestões de procedimentos metodológicos elaboradas algumas aulas mais adiante.

Em um trabalho temos: "O estudo desta temática é relevante para o alunado, pois contribuirá para o rompimento dos preconceitos existentes com relação a religiosidade ...; O objetivo desta temática é estabelecer um paralelo entre o pensamento religioso dos dois países". Sua proposta metodológica, 
entretanto, não consegue sair dos moldes das aulas expositivas e dependentes do livro didático: "Na primeira aula, a metodologia a ser usada será a de utilização de contato verbal entre o professor e aluno, a professora irá introduzir o assunto à turma ..., logo em seguida ela utilizará a metodologia de ensino através do próprio livro".

Em outro exemplo, o objetivo é: “As habilidades que serão utilizadas para execução desse trabalho partirão da análise e interpretação de diferentes fontes e linguagens a partir de imagens, texto, objetos etc. e comparação de informações ...”. A metodologia, entretanto, sugere: "Levantamento dos conhecimentos prévios dos alunos ...; exposição da temática e discussão coletiva ...; exposição de cartazes".

A dificuldade em materializar a intenção dos objetivos em procedimentos metodológicos nos parece resultante da permanência de uma relação com a História semelhante àquela estabelecida em outros níveis de ensino. Supondo que esses alunos tenham aprendido a História da forma que muitos chamam de tradicional na sala de aula, o que fica evidente é o fato de continuarem a conceber o conhecimento histórico como 'passado', como um saber que consiste em processo histórico - acontecimentos e personagens em uma narrativa linear - delimitado pelos cânones historiográficos presentes nos livros didáticos. O espaço deste artigo não comporta discutir a legitimidade ou não dessa dita história tradicional na educação básica. Nos importa o fato de que o conteúdo de uma graduação deva habilitar o graduando a compreender a construção da História e não somente se ater a uma narrativa que assume o efeito de passado. É bem verdade que a experiência acumulada ao longo dos anos é que o fará apurar cada vez mais a História que produz, e para isso existem os programas de pós-graduação e as carreiras profissionais - na docência, no patrimônio, nos lugares de memória. Mesmo esse momento inicial que é a graduação não prescinde de que o aluno saiba adquirir certa autonomia na seleção de suas temáticas; no entanto, eles mantêm a mesma relação de dependência com o texto. Em outras palavras: História é o passado, que é o texto que se lê nos livros didáticos, comportamento que se perpetua nas nossas disciplinas acadêmicas.

Reproduzimos na universidade a mesma forma de estudar a que esses alunos estão acostumados. Os conteúdos programáticos de nossos programas se organizam pelos títulos dos textos que selecionamos para leitura. Até que 
ponto é possível equacionar nossos objetivos entre procedimentos metodológicos da História - capacidade de síntese e interpretação de fontes, análise e comparação historiográfica, formas de apresentação da História e linguagens historiográficas - e o conteúdo factual, sem os quais tampouco há História?

A própria estrutura curricular dos cursos de formação de profissionais de História é digna de revisão. Se após os debates historiográficos do século XX se insiste tanto na flexibilidade dos recortes temporais e da periodização, uma vez que os próprios documentos curriculares para o ensino fundamental caminham para uma história por eixos temáticos e enfatizam o caráter de construção da História, lembrando que também o quadripartismo é histórico e resultado de interesses, como já denunciava Chesnaux, ${ }^{2}$ nossas disciplinas continuam refletindo o processo histórico - da Pré-História até a História Contemporânea, passando por Brasil e pelas histórias dos estados - mais do que o fazer histórico. Mesmo assim, exigimos que nossos alunos saibam transitar entre as diferentes temporalidades, que saibam periodizar de acordo com seus objetos de estudo e, mais grave ainda, que saibam ensinar essa habilidade a outros indivíduos que ainda estão em processo de desenvolvimento cognitivo.

Essas impressões iniciais foram constatadas à medida que progredimos na disciplina. O passo seguinte ao estabelecimento dos objetivos era a pesquisa acerca da temática nas historiografias acadêmica e didática - como os assuntos eram tratados pelos livros acadêmicos e pelos livros didáticos?

Mais uma vez, obtivemos respostas mais elaboradas e respostas que serviram para novas indagações. Por exemplo:

a) A historiografia didática dá uma percepção de uma produção narrativa histórica linear, que apresenta um quadro de periodização e de balizas espaciais e temporais com o intuito de delimitar para os alunos uma melhor compreensão sobre o tema proposto ... A historiografia acadêmica, ao contrário da historiografia didática, busca problematizar o evento ocorrido ... propiciando vários questionamentos e trazendo para a discussão os reais motivos que impulsionaram a vinda da corte ao Rio de Janeiro.

b) O livro didático aborda a temática de um modo geral e objetivo abrangendo os pontos principais desta religião, usa uma linguagem de fácil 
entendimento e explicação para seu público alvo que se trata de crianças. O livro didático em seu conteúdo destaca os principais pontos a qual a religião está ligada ... Na visão acadêmica, o autor Ciro Flammarion aborda a temática de forma ampla e objetiva, ele destaca de um modo mais profundo a questão da religião ligada a vida política, econômica e social da civilização egípcia. Ele retrata também a questão das crenças nos deuses e se aprofunda na questão de como os egípcios lidavam com a morte...

c) E a diferença é que na academia o estudo é mais aprofundado quando na escola é explanado de forma mais sucinta.

À pergunta "Como a temática é abordada nas historiografias acadêmica e didática?", as três amostras de resposta nos revelam como alguns graduandos realizam a leitura de um texto e a análise de uma temática: centrando-se na detecção de quantos fatos históricos cada um abordava. É por isso que o último exemplo resume a impressão geral obtida das respostas: um é mais aprofundado, supostamente teria mais detalhes e explicações, ao passo que outro é mais curto, sintético.

Parece-nos razoável atribuir essa lógica de interpretação ao caráter informativo da História a que os alunos são submetidos durante a escolarização básica. A diferença entre os níveis de ensino para esses alunos se caracteriza mais pelo acúmulo e acréscimo de informações de um nível para o outro (algo de que o ensino superior não está livre, como se verifica) do que pelo trabalho no desenvolvimento de uma consciência histórica, o que exigiria o encadeamento de habilidades específicas para cada etapa de aprendizagem.

Porém, podemos citar respostas que caminham para um entendimento mais elaborado da construção do conhecimento histórico:

d) Em seu livro A Civilização do Ocidente Medieval, Le Goff afirma que o sistema feudal não foi uniforme em toda Europa, se adaptou a cada região e país em que foi aderido. Ele afirma também que as relações de poder ... não ocorriam apenas entre os senhores feudais e seus servos, ela se encontrava em todas as escalas da sociedade ... A partir das análises aqui realizadas convém observar que hoje a historiografia didática tem buscado disponibilizar aos estudantes uma visão mais contemporânea das pesquisas sobre a temática ... É importante que se 
destaque que os livros didáticos propõem-se a trabalhar com múltiplos e diversos conteúdos, o que leva-o a ser sintético em suas abordagens, o que difere das discussões acadêmicas, onde retratam-se conteúdos específicos, não havendo a preocupação com o processo de ensino e aprendizagem, o que nos leva a discutir os temas que trabalhamos de modo mais crítico.

Nessa resposta, ainda que se tenha a permanência de um olhar sobre o conteúdo factual da temática escolhida ("Le Goff afirma que...", "o que leva-o a ser sintético...”), levam-se em consideração os objetivos de cada um dos textos analisados, como o caráter heterogêneo dos textos didáticos, revelando uma visão que não reduz a diferença entre um e outro somente à quantidade de conteúdos que cada um aporta.

No exemplo seguinte podemos visualizar um esforço de interpretação mais elaborado acerca de como se constrói um texto historiográfico:

e) Analisando a historiografia didática a partir do livro ... percebe-se no que diz respeito ao recorte temporal que ela trabalha de uma maneira linear e sintética-factual, visando a melhor sistematização de informações, apresenta a estrutura física da sociedade em aldeias, nomos e reinos ... No que diz respeito aos recursos visuais na historiografia didática, todas as imagens fazem referência ao papel de cada indivíduo na estrutura política, por exemplo, nas pinturas mostra a figura do faraó, do escriba ... Em relação aos exercícios contidos no livro didático identificamos a preocupação do autor em paralelizar a temática em discussão ... Em contrapartida, a historiografia acadêmica, segundo Ciro Cardoso, Perry Anderson e outros partem do pressuposto do modo de produção asiático, onde é explícito a presença do materialismo histórico de Karl Marx, o mesmo prega a luta de classes, opressor $\mathrm{x}$ oprimido. Nesta contextualização o objeto de estudo que ganha destaque é a classe servil composta pelos camponeses e escravos ... Em relação às fontes que a historiografia acadêmica utiliza podemos citar as observações arqueológicas no que diz respeito à análise de tumbas ... Já em se tratando de análise literária, podemos citar obras como ...

Vê-se agora um olhar que considera não somente a quantidade de conteúdo de cada um dos textos, mas também sua forma: periodização; formas de 
utilização de recursos (imagens e tipos de fontes); tipo de conhecimento validado pelos exercícios e até mesmo um ensaio de interpretação teórica (modo de produção asiático, materialismo histórico).

Aqui se constata o reconhecimento dos dois sentidos básicos da palavra História na leitura dos textos analisados, tanto no nível do processo histórico - o que se sabe sobre a temática - quanto no nível do conhecimento histórico - como se sabe sobre a temática. Isso se traduziu em uma proposta metodológica que não se prendeu somente aos conteúdos factuais, mas valorizou conteúdos conceituais e análise de estruturas (civilização, política, mobilidade social), e também outros conteúdos procedimentais: “Após essa problematização pediremos que os alunos identifiquem essas questões e as reproduzam por meio de desenhos ou texto escrito; nesse trabalho avaliaremos as suas capacidades de síntese e redação, ou seja, a capacidade do alunado em organizar e produzir sua narrativa histórica”.

As respostas obtidas nos levaram a mais uma vez indagar sobre nossos próprios procedimentos na sala de aula universitária: Como trabalhar para diminuir a dificuldade dos alunos em realizarem uma análise que extrapole a identificação de quais fatos certo texto contém? A habilidade de perceber como um texto historiográfico é construído é exigida dos alunos? Trabalhamos com eles os 'alicerces e fundações' de um texto, ou permanecemos somente na sua 'fachada'?

Verificamos que para o manejo mais seguro de práticas que atendam às discussões sobre o ensino de História hoje, nos níveis fundamental e médio, é preciso rever nossas práticas no ensino superior de modo que possam romper significativamente as pré-concepções que esses alunos carregam, ou, em linguagem mais familiar para muitos - transformar seus conhecimentos prévios acerca do que é História.

Se essa experiência de docência nos despertou para os elementos que constituem o processo de ensino-aprendizagem no tocante aos alunos - professores em formação -, outra experiência de pesquisa realizada nos forneceu elementos para compreender o processo de ensino-aprendizagem tendo como referência a outra parte desse processo: os professores universitários - formadores de professores. 


\section{OS FORMADORES DE PROFESSORES}

As observações feitas neste tópico resultam de pesquisa realizada em outro momento, cujo objetivo era compreender a implantação do Projeto Pedagógico do curso de História da Universidade Federal do Rio Grande do Norte.

Buscando o componente que dá vida ao texto do Projeto PolíticoPedagógico (PPP), que de certa forma finda por ser homogeneizador, visto falar em nome da coletividade, buscamos ouvir os seres humanos que estão conectados através do Projeto, pois são estes que lhe conferem legitimidade ou não, que se apropriam, que o executa, que o remodela, estendendo o processo para além do documento escrito e buscando o currículo vivido pelo alunos e pelos professores. Concordamos com Sacristán no tratamento do caráter vivo dos currículos:

Um campo do conhecimento é, antes de mais nada, uma comunidade de especialistas e professores que compartilham uma parcela do saber ou determinado discurso intelectual, com a preocupação de realizar contribuições para o mesmo. Não estamos frente a uma visão acabada ou frente à crença de estar diante de algo dado e monolítico, mas, pelo contrário, frente a uma comunidade que tem dimensões internas e onde seus membros realizam tarefas que diferem entre si ... Nessa comunidade com diferentes encargos se produzem desconexões e falta de comunicação importantes. Não é fácil encontrar referências nos currículos a esse caráter vivo, histórico e nem sempre coerente dos saberes como campo de atividade humana. ${ }^{3}$

Para o nosso estudo do PPP de História da UFRN, utilizamos como fontes as entrevistas com professores, um momento privilegiado no qual percebemos a polifonia por trás de um documento único (o Projeto Político-Pedagógico) e que nos possibilita buscar esse "caráter vivo, histórico e nem sempre coerente" de que fala Sacristán (2000, p.68).

Partindo do pressuposto de que não é possível deixar de lado questões sobre a construção do currículo pelo seu corpo docente e de que este, sendo parte de uma instituição de ensino superior, logo portador de determinadas responsabilidades, configura práticas que fazem parte da constituição de um campo científico - campo este dentro do qual os alunos são formados -, 
passemos agora à abordagem de alguns tópicos importantes na execução de um currículo, frequentemente lembrados quando se fala em ensino superior. Em texto não publicado, para fins de anotação para uma reunião interna da Pró-Reitoria de Graduação da UFRN, a professora Lúcia resume estas questões:

Uma outra fragilidade observada no processo de organização dos cursos refere-se à sua gestão. Na maioria dos cursos há muita dificuldade em acompanhar e controlar o processo de execução do PPC (projeto pedagógico de curso). O pacto coletivo, exigência do projeto pedagógico, ainda não foi transposto do documento para a prática docente. A interdisciplinaridade e a flexibilidade, princípios basilares da organização dos conhecimentos nas estruturas curriculares, têm sido inviabilizadas pela postura dos professores, que têm o mandato de suas disciplinas, não se dispõem a fazer as mudanças propostas e a rever conteúdos. Ao contrário, se isolam em seus laboratórios, demonstrando que o poder investido ao professor pela cátedra vitalícia ainda faz parte da cultura universitária. Diante da atitude desses professores, os coordenadores de cursos se veem impotentes, e as mudanças propostas para reorganização dos currículos permanecem na intenção expressa no documento. Prevalecem as estruturas curriculares rígidas, as disciplinas com um caráter de terminalidade, dificultando a conexão de saberes e práticas na formação do aluno. ${ }^{4}$

Preocupamo-nos em investigar a relação entre os professores no Departamento de História, como norteiam sua prática de sala de aula (em que elementos eles baseiam o exercício da profissão de professor universitário).

Tomando como premissa o fato de os professores serem mediadores do currículo, lembramos que o envolvimento e a participação coletiva, ou ao menos o reconhecimento de que deveria ser assim, são necessários para a concretização de uma proposta curricular. Lembramos também que este foi um dos grandes compromissos do Projeto Político-Pedagógico: o engajamento do seu corpo docente nesse novo projeto comum.

Preservando-se a margem de autonomia individual no relacionamento com o currículo, é com base nele que se constitui uma identidade do curso, um propósito para os 4 anos que se planejam ali; 4 anos que devem ser estruturados sob uma lógica que lhes dê coerência, coesão e continuidade, pressupondo o exercício de uma articulação entre seus integrantes. A maior parte de seus objetivos, aliás, consta como de competência de todos, como coletividade. 
Ao longo das entrevistas pudemos perceber que boa parte das explanações relatadas pelos professores acerca dos fatores que interferiam no planejamento de suas práticas docentes referiam-se à sua própria experiência enquanto alunos, o que entendiam que deveria ser o profissional de História, sendo isso transposto para as aulas. A seguir, vejamos como isso se revelou.

Respondendo sobre a maneira como percebia a construção coletiva do novo Projeto, o professor A afirmou que uma parte do corpo docente mal conhecia o PPP. E completou:

Mas mesmo que conhecessem, acho que isso também vai muito mais além. Aí é muito da concepção que se tem da universidade, ou que prevaleceu de uma maneira hegemônica, hoje menos: "Ah, o professor tem autonomia pra desenvolver seu plano de curso, desenvolve da maneira que quer". Um pouco, ainda, o resquício daquela coisa da cátedra, que vem diminuindo, mas ainda é bastante presente. Eu vejo um pouco isso: a resistência da própria formação dos professores. Aí é uma coisa que demora muito tempo, às vezes o professor tem uma concepção de ensino-aprendizagem que não bate exatamente com o que foi pensado no PPP, já é uma dificuldade. (Entrevista com professor A, em Costa, 2010)

Queremos destacar nessa resposta a atribuição desse desconhecimento sobre o PPP e da falta de engajamento à formação dos professores. Pelas respostas dadas, pareceu-nos que a formação própria de cada um constitui-se em marco de referência para o exercício da docência. Por exemplo, o professor B faz várias referências à sua graduação como referencial para o seu julgamento sobre o que deveria ser ou não bom:

Eu peço as monografias de sempre porque eu estudei assim e foi bom no sentido de "foi bom, deu certo e vou repetir".

A minha formação nos anos 80 em relação à Licenciatura e Bacharelado eu achava muito simples e prática e acho que era a solução que devia ser adotada aqui. O estudante entrava para ser potencialmente os dois, só que a opção por ser um licenciado vinha nos últimos períodos, quando nós pagávamos determinadas disciplinas na Faculdade de Educação. E quem quisesse concluía, quem quisesse não concluía.

Essa seria minha solução ideal. Por isso que eu digo que ao mesmo tempo possa achar ... por isso ou por aquilo, o fundamento é conservador, que foi a minha experiência que eu achei boa. (Entrevista com professor B, em Santos, 2010) 
Nisso não há muita novidade: são as instâncias pelas quais passaram e que lhes conferiram um ofício e um diploma e, portanto, meios para aceder aos postos ocupados atualmente.

Maurice Tardif, no texto "Saberes Profissionais dos Professores e Conhecimentos Universitários”, ressalta três aspectos do caráter temporal que caracterizaria os saberes docentes: primeiro, "uma boa parte do que os professores sabem sobre o ensino, sobre os papéis do professor e sobre como ensinar provém de sua própria história de vida e, sobretudo, de sua história de vida escolar". Os outros dois aspectos referem-se aos fatos de os primeiros anos serem decisivos na estruturação da prática profissional e os saberes serem utilizados e adquiridos no âmbito de uma carreira/socialização profissional. É certo que Tardif refere-se, predominantemente, aos professores do que seria o correspondente americano e canadense ao nosso ensino fundamental e médio. No entanto, acreditamos que essa pode ser uma afirmação também válida para o que ocorre com os professores universitários, em especial se nos detivermos sobre as prescrições acerca da formação de professores para o nível superior. ${ }^{5}$

A Lei de Diretrizes e Bases da Educação Nacional sobre o tema da formação docente para o nível superior afirma que: “Art. 66. A preparação para o exercício do magistério superior far-se-á em nível de pós-graduação, prioritariamente em programas de mestrado e doutorado". ${ }^{6}$ Em sendo assim, seria de esperar que houvesse algo a respeito do assunto na legislação sobre os cursos de pós-graduação stricto sensu. Porém, na Resolução CNE/CES no 1,7 de 3 de abril de 2001, que estabelece normas para o funcionamento de cursos de pós-graduação, não há menção a isso. De modo que:

A formação docente para a educação superior fica, portanto, a cargo das iniciativas individuais e dos regimentos das instituições responsáveis pela oferta de cursos de pós-graduação. O governo (MEC/Sesu/Capes/Inep) determina os parâmetros de qualidade institucional, e muitas instituições de educação superior organizam e desenvolvem um programa de preparação de seus docentes, orientadas por tais parâmetros. ${ }^{8}$

Em um cenário já marcado pela relação conflituosa entre conhecimentos específicos e pedagógicos, entre teoria e prática, ensino e pesquisa, Bacharelados e Licenciaturas, são os parâmetros de avaliação de produtividade acadêmica 
que findam por orientar o que seria a atividade docente. Também pensamos ser esse um dos fatores que contribui para a afirmação de Miguel Zabalza: "Não se deve estranhar que nós, professores universitários, tendamos a construir nossa identidade profissional em torno da produção científica ou das atividades produtivas que geram mérito acadêmico e que redundam em benefícios econômicos e profissionais. Isso pode ser chamado, utilizando a denominação de Vandenberghe, de a ética da praticidade". ${ }^{9}$

$\mathrm{O}$ fato de as atividades docentes poderem ser marcadas mais pela repetição de experiências de vida escolar, considerando como ponto chave o momento da graduação - em referência ao exemplo do professor B -, permite-nos a compreensão de falas como a do professor A, que cita a resistência dos docentes e os resquícios dos períodos de suas formações, como, por exemplo, as cátedras.

Lembrando que a formação dos professores universitários depende, como disse Ilma Veiga, das iniciativas individuais das instituições responsáveis pelos cursos de pós-graduação, essas iniciativas, na maioria das vezes, são compostas pelos estágios-docência obrigatórios realizados pelos pós-graduandos que são bolsistas. Mas não fazem parte do conjunto de componentes curriculares comuns a todos - o interessado deve se dispor a segui-los.

São esses os quesitos que permitem o ingresso nas vagas para professores universitários, portanto não é de causar estranheza que os padrões de um bom exercício docente sejam aqueles pelos quais se passou: a graduação, marcada pelo contexto histórico do período em que foi cursada, as etapas pelas quais se passou - mestrado e doutorado - para finalmente atingir o referido posto.

Por conta dos parâmetros dominantes sobre o que seria a atividade do professor universitário, a identidade de historiador - título dado aos professores universitários sem contestação, e que se constitui sobre esses alicerces -, não há (e aqui lançamos mão mais uma vez dessa expressão) uma ampliação de perspectiva, pois as relações que se estabelecem com outras circunstâncias e atuações que não a dos 'habitus científicos' ou são frágeis ou são exceções. Um grande exemplo são as relações entre universidade e ensino básico, fartamente discutidas e criticadas.

Isso nos ajuda a apreender, por exemplo, a dificuldade em se entender e se aplicar a Prática como Componente Curricular, pois não há visão ou mesmo imaginação capaz de ir além daquilo que se está acostumado a ter como ofício 
do historiador: o trabalho individual e o círculo acadêmico (além, é claro, de as implicações de resoluções como essa frequentemente 'caírem no colo' dos professores, culpa atribuída às instâncias superiores, mas também ao corpo universitário, professores e alunos, cuja maioria não se envolve nessas questões). Ou então as Atividades Acadêmico-Científico-Culturais, que acompanham uma classificação muitas vezes seguida pelos próprios professores para fins de progressão de carreira.

Assim, o que sobra aos alunos são as reproduções de habitus científicos - como chama Bourdieu. ${ }^{10} \mathrm{O}$ que conta como conhecimento histórico continua sendo, em grande medida, marcado pelo conteúdo e pelas práticas em que é trabalhado, pois é em torno disso que se constroem as identidades.

É um conteúdo que reproduz práticas acadêmicas e que limita a formação dos graduandos, pois que restrito a certos parâmetros e círculos, os quais reproduzem uma 'ordem científica estabelecida', fruto de um campo de forças científicas tanto quanto políticas, cujos árbitros costumam estabelecer as próprias regras do jogo (Bourdieu, 1983).

Desse modo, a discussão ganha outra dimensão, pois seria necessário rever a formação de quadros para o ensino superior, repensando, portanto, nos programas de pós-graduação, a existência de um interesse mais profundo na preparação e formação para o exercício da docência universitária que ultrapasse os limites dos conteúdos da pesquisa de cada pós-graduando.

Some-se a isso a revisão sobre os processos de formação continuada entre os próprios quadros das universidades, de modo que as diferenças entre gerações pudessem ser discutidas e atenuadas, proporcionando uma atualização em termos de objetivos da instituição. Mais uma vez - salvo exceções - acreditamos que o individualismo tende a favorecer a imobilidade e a estagnação, conduzindo ao aumento das diferenças entre os professores.

\section{CONSIDERAÇÕES FINAIS}

Gostaríamos aqui de lançar mão da noção de profissionalização didática dos historiadores, proposta por Jörn Rüsen, em que esta pode vir a auxiliar na formação de uma "concepção sólida da especialidade profissional de sua ciência". ${ }^{11}$ Uma teoria da História, para Rüsen, dialoga com o ensino superior guiando os historiadores em formação em meio aos mecanismos de funcionamento de sua 
ciência, de maneira que possam produzir conscientemente no lugar de reproduzir ou consumir um conhecimento imposto por outrem.

O ensino superior de História deve, a nosso ver, atender dois quesitos, um derivado do outro: o primeiro é justamente a formação para a produção de pesquisa, o ensino de História ou o uso do conhecimento histórico onde seja demandado; o segundo é a aquisição da competência necessária para compreender o lugar do conhecimento histórico especializado em meio às diferentes relações que as sociedades estabelecem com o tempo. Não é suficiente que só se aprenda a produzir conhecimento histórico - é preciso também compreender os mecanismos de sua produção: como surge, de que surge, como se transforma em conhecimento específico, o que constitui esse conhecimento. É nesse ponto que acreditamos residir uma das características definidoras desse nível de ensino.

Portanto, se é isso que determina e diferencia o trabalho do historiador - o entendimento de que a produção de um conhecimento que estabelece relações entre passado e presente pode ser específico, possui características próprias e é executado por meio de regras, frutos de reflexões teórico-metodológicas -, então é isso que poderia ser tomado como eixo norteador dos cursos de graduação em História, espaços de aquisição e produção de conhecimento histórico e, por que não, mão de obra para manejar esse saber.

É possível estabelecer essa conexão? Acreditamos que sim. Por entender que o núcleo da formação desse profissional reside justamente no conhecimento sobre as ferramentas de seu trabalho e nos objetivos da produção do conhecimento é que não fazemos distinção entre bacharel e licenciado. E é por isso que enfatizamos a prática, o saber manejar as ferramentas, a pesquisa, pois qualquer que seja o espaço de atuação, o resultado de seu trabalho deriva de uma pesquisa que será transladada, aplicada, para onde estiver em ação. É por isso que não se pode considerar pesquisa, aqui, algo unicamente produzido para atender aos objetivos da academia ou nos moldes dela, mas sim, a base de trabalho do historiador, a sua operação básica - a operação historiográfica -, a qual ele terá de exercer em qualquer que seja seu espaço de atuação. A sensibilidade e o treino para compreender as carências de orientação temporal que a vida prática nos impõe e a formação adequada para saber ler essas carências e trabalhá-las pela perspectiva da disciplina, de suas discussões teórico-metodológicas.

O desafio que se coloca perante nós agora é este: o de transformar essa discussão em realidade no cotidiano das salas de aula universitárias. 
Na realidade, o que se propõe aqui é prestarmos atenção em como nossos alunos estudam e aprendem a História na (e da) graduação. Quando nos perguntamos "por que, quando planejam aulas, reproduzem comportamentos já tão criticados?", a resposta parece ser que a maioria, afora os beneficiados por bolsas de iniciação científica ou iniciação à docência, continua estudando História da mesma forma como o fazia na escola. Temos, aliás, o reconhecimento por parte de professores universitários de que continuam fortemente marcados pela sua própria experiência enquanto graduandos. Em verdade, essa conclusão não chega a ser exatamente uma novidade. Como já citado, Maurice Tardif lembra, com base em pesquisas a respeito da carreira e dos saberes docentes, a predominância da experiência da vida escolar sobre a atuação docente. E afirma que "Essa imersão se manifesta através de toda uma bagagem de conhecimentos anteriores, de crenças, de representações e de certezas sobre a prática docente. Esses fenômenos permanecem fortes e estáveis ao longo do tempo" (Tardif, 2000, p.13).

Nossa experiência na disciplina de Metodologia do Ensino de História nos revelou, portanto, que, ao menos para aquela turma, se ensina História como se aprende História. Com base nessa indicação, se faz necessário discutir como o conhecimento acerca da prática historiográfica e do ensino de História construído durante a graduação pode atuar no sentido de 'abalar' as representações dos alunos a respeito de como se ensina História, contribuindo para o exercício de uma prática docente pela qual tanto se combate na contemporaneidade.

Se os alunos demonstraram repetir procedimentos aprendidos durante a vida escolar no seu planejamento de aulas, não é porque simplesmente não saibam pesquisar, mas sim porque não dominam as habilidades necessárias para fazer História, e consequentemente, para praticá-las em sala de aula. Sua insegurança no tocante às questões metodológicas impede que consigam manejar a distinção entre os sentidos da História - enquanto processo histórico e enquanto conhecimento sobre esse processo -, predeterminando suas leituras, estudos e interpretação no nível do factual, tomando o texto escrito pelo processo histórico. Assim é que tivemos estas etapas de aula: "trabalhar com os alunos o conteúdo em sala de aula utilizando tudo o que foi exposto pelo livro"; "será planejada uma atividade avaliativa para a turma seguindo os padrões de tudo o que foi exposto pelo livro e pela professora"; "usarei o quadro escrevendo as causas que levaram a ocorrer a Revolução Francesa ... Farei uma retrospectiva de tudo 
que já foi passado em sala. Encerrarei a aula pedindo a cada um o que foi passado, ou seja, o que ficou na mente de todos".

Por isso nosso incômodo diante da justificativa baseada no senso comum de que "para ensinar o professor precisa pesquisar". Temos percebido que não é necessariamente a prática da pesquisa que tornará nossos alunos melhores professores. Os exemplos aqui reunidos nos mostraram que muitas vezes uma pesquisa pode se resumir a identificar quanto cada autor diz sobre determinado assunto, e convenhamos, isso não é necessariamente pesquisar, tampouco fazer História. É preciso que os historiadores e especialmente aqueles que formam as próximas gerações de profissionais se voltem para o ainda mais básico, para o que é necessário antes do ato de pesquisar, que é compreender as categorias básicas do fazer histórico, no que se traduz em discussões metodológicas, bem como compreender a função social da História - o que eu quero dizer quando produzo História? Por que e para que o faço? -, a que podemos chegar com base na teoria. Sem isso, como vimos, torna-se muito difícil para nossos alunos atingirem os objetivos do ensino proposto pelos documentos curriculares e pelas discussões da área, visto que a História se configura somente em acúmulo de fatos. Obviamente, há outros fatores a serem levados em consideração. Citando mais uma vez Tardif,

Desse ponto de vista, a prática profissional nunca é um espaço de aplicação dos conhecimentos universitários. Ela é, na melhor das hipóteses, um processo de filtração que os dilui e os transforma em função das exigências do trabalho; ela é, na pior das hipóteses, um muro contra o qual se vêm jogar e morrer conhecimentos universitários considerados inúteis, sem relação com a realidade do trabalho docente diário nem com os contextos concretos de exercício da função docente. (Tardif, 2000, p.12)

Porém, isso não significa que aquilo chamado pelo autor de 'conhecimentos universitários' não precise ser útil e significativo para a formação do graduando. E que no nosso caso, sirvam para distinguir entre a História que aprendem na escola e fora dela durante a educação básica com a História aprendida na graduação, não somente para a atuação em sala de aula, mas também para os outros espaços que demandam a presença de um historiador: museus, arquivos, setores do turismo e preservação de patrimônio, entre outros. 
Para tanto precisamos reconhecer a existência de um processo de ensino e aprendizagem de jovens e adultos também no ensino superior, o que pode vir a significar igualmente o reconhecimento e a investigação de uma didática da História específica referente ao aprendizado da cultura profissional do historiador.

\section{NOTAS}

${ }^{1}$ NEVES, Joana. Participação da comunidade, ensino de história e cultura histórica. Saeculum: Revista de História, João Pessoa: DH/PPGH/UFPB, n.6/7, p.35-47, jan. 2000-dez. 2001. p.46.

${ }^{2}$ CHESNEAUX, Jean. Devemos fazer tábula rasa do passado? Sobre a História e os historiadores. São Paulo: Ática, 1995.

${ }^{3}$ SACRISTÁN, J. GIMENO. Currículo: uma reflexão sobre a prática. 3.ed. Porto Alegre: Artes Médicas, 2000. p.68.

${ }^{4}$ SANTOS, Maria Lúcia Ferreira. Anotações para reunião do POSGRAD. Natal, RN, s.d., apud COSTA, Aryana. A formação de profissionais de História: o caso da UFRN (20042008). Dissertação (Mestrado) - Programa de Pós-Graduação em História, Universidade Federal da Paraíba. João Pessoa, 2010. p.120

${ }^{5}$ TARDIF, Maurice. Saberes profissionais dos professores e conhecimentos universitários: elementos para uma epistemologia da prática profissional dos professores e suas consequências em relação à formação para o magistério. Revista Brasileira de Educação, n.13. p.5-24, jan.-abr. 2000. p.13.

${ }^{6}$ BRASIL. Lei no 9.394, de 20 dez. 1996. Estabelece as diretrizes e bases da educação nacional. Disponível em: www.planalto.gov.br/ccivil_03/leis/19394.htm; Acesso em: 25 fev. 2013.

${ }^{7}$ BRASIL. Ministério da Educação. Resolução CNE/CES no 1, de 3 abr. 2001. Estabelece normas para o funcionamento de cursos de pós-graduação lato sensu, em nível de especialização. Disponível em: http://portal.mec.gov.br/cne/arquivos/pdf/rces001_07.pdf; Acesso em: 25 fev. 2013.

${ }^{8}$ VEIGA, Ilma P. A. Docência universitária na educação superior. In: Docência na educação superior. Brasília: Inep, 2006. p.87-98. (Coleção Educação Superior em Debate, v.5). ${ }^{9}$ ZABALZA, Miguel A. O ensino universitário: seu cenário e seus protagonistas. Porto Alegre: Artes Médicas, 2004. p.103.

${ }^{10}$ BOURDIEU, Pierre. O campo científico. In: ORTIZ, Renato (Org.). Pierre Bourdieu. São Paulo: Ática, 1983. p.122-155.

${ }^{11}$ RÜSEN, Jörn. A razão histórica. Brasília: Ed. UnB, 2001. p.38.

Artigo recebido em 20 de dezembro de 2012. Aprovado em 14 de abril de 2013. 